\title{
Kringle-containing Fragments of Apolipoprotein(a) Circulate in Human Plasma and Are Excreted into the Urine
}

\author{
Vincent Mooser, ${ }^{\star}$ Santica M. Marcovina, ${ }^{\ddagger}$ Ann L. White, ${ }^{\S}$ and Helen H. Hobbs ${ }^{\star}$ \\ *Departments of Internal Medicine and Molecular Genetics, University of Texas Southwestern Medical Center, Dallas, Texas 75235; \\ ${ }^{\ddagger}$ Department of Medicine, Northwest Lipid Research Laboratory, University of Washington, Seattle, Washington 98103; and ${ }^{\S}$ Southwest \\ Foundation for Biomedical Research, San Antonio, Texas 78228
}

\begin{abstract}
Apolipoprotein(a) [apo(a)] contains multiple kringle 4 repeats and circulates as part of lipoprotein(a) $[\mathrm{Lp}(\mathrm{a})]$. Apo(a) is synthesized by the liver but its clearance mechanism is unknown. Previously, we showed that kringle 4-containing fragments of apo(a) are present in human urine. To probe their origin, human plasma was examined and a series of apo(a) immunoreactive peptides larger in size than urinary fragments was identified. The concentration of apo(a) fragments in plasma was directly related to the plasma level of $\mathrm{Lp}$ (a) and the 24-h urinary excretion of apo(a). Individuals with low ( $<2 \mathrm{mg} / \mathrm{dl}$ ) plasma levels of $\mathrm{Lp}(\mathrm{a})$ had proportionally more apo(a) circulating as fragments in their plasma. Similar apo(a) fragments were identified in baboon plasma but not in conditioned media from primary cultures of baboon hepatocytes, suggesting that the apo(a) fragments are generated from circulating apo(a) or $\operatorname{Lp}(\mathrm{a})$. When apo(a) fragments purified from human plasma were injected intravenously into mice, a species that does not produce apo(a), apo(a) fragments similar to those found in human urine were readily detected in mouse urine. Thus, we propose that apo(a) fragments in human plasma are derived from circulating apo(a)/Lp(a) and are the source of urinary apo(a). $(J$. Clin. Invest. 1996. 98:2414-2424.) Key words: lipoprotein(a) • kidney $\bullet$ heparin $\bullet$ monkey $\bullet$ mouse
\end{abstract}

\section{Introduction}

Apolipoprotein(a) $[\operatorname{apo}(a)]$ is covalently attached to the apolipoproteinB100 (apo-B100) of low density lipoprotein (LDL) and circulates in plasma as lipoprotein(a) $[\mathrm{Lp}(\mathrm{a})]^{1}(1) . \mathrm{Lp}(\mathrm{a})$ is of clinical interest because numerous cross-sectional as well as prospective studies have shown that high plasma levels of $\mathrm{Lp}(\mathrm{a})$ are an independent risk factor for cardiovascular dis-

Address correspondence to Helen H. Hobbs, M.D., Department of Molecular Genetics, UT Southwestern Medical Center at Dallas, 5323 Harry Hines Blvd., Dallas, TX 75235-9046. Phone: 214-6486724; FAX: 214-648-7539; E-mail: Hhobbs@mednet.swmed.edu

Received for publication 28 June 1996 and accepted in revised form 11 September 1996.

1. Abbreviations used in this paper: $\mathrm{CRF}$, chronic renal failure; $\mathrm{K}$, kringle; Lp(a), lipoprotein(a); t-PA, tissue plasminogen activator.

J. Clin. Invest.

(c) The American Society for Clinical Investigation, Inc. 0021-9738/96/11/2414/11 \$2.00

Volume 98, Number 10, November 1996, 2414-2424 eases (2). Multiple mechanisms have been proposed to be responsible for the link between $\mathrm{Lp}(\mathrm{a})$ and atherosclerosis but none have been shown conclusively to be operative in vivo (3). Individuals who have little to no detectable $\mathrm{Lp}(\mathrm{a})$ in their plasma are apparently healthy, which has raised the question as to the physiological role of apo(a).

Apo(a) contains a variable number of a cysteine-rich, $\sim 114$ amino acid protein motif referred to as a kringle (K). Each $\mathrm{K}$ contains three disulfide bonds that form three protein loops. Apo(a) is a member of a family of K-containing proteins that includes prothrombin, Factor XII, tissue plasminogen activator (t-PA), urokinase, plasminogen, macrophage stimulating protein, and hepatocyte growth factor $(4,5)$. These proteins all contain a fixed number of Ks, whereas the number of $\mathrm{Ks}$ in apo(a) varies from 12 to 51 between different apo(a) isoforms. 10 different types of $\mathrm{K} 4$ repeats, arbitrarily designated K4-type 1 to K4-type 10 (6), are present in apo(a). Each type of K4 repeat is found as a single copy in apo(a), except the K4-type 2 repeat, which is reiterated 3-42 times (7). Following the tandem array of $\mathrm{K} 4$ repeats, apo(a) has a single K5 followed by a sequence that shares $94 \%$ sequence identity with the protease domain of plasminogen (8). Unlike plasminogen, which is cleaved by t-PA to release plasmin, apo(a) is not cleaved by t-PA and the protease domain has not been shown convincingly to have protease activity in vivo.

The K domain of apo(a) and other K-containing family members targets the proteins to particular tissues by binding to proteoglycans and other components of the extracellular matrix $(9,10)$. The recent observation that the K-containing region of plasminogen may have biological functions other than tissue targeting has expanded the potential role of these protein motifs. A 38-kD peptide corresponding to the first four $\mathrm{K}$ repeats $(\mathrm{K} 1-\mathrm{K} 4)$ of plasminogen has been shown to have antiangiogenic effects both in vitro and in vivo (11). This observation prompted us to explore whether apo(a) may also generate $\mathrm{K}$-containing fragments that are possibly biologically active.

Human urine contains a series of apo(a)-derived, K4-containing fragments ranging in size from 85 to $215 \mathrm{kD}(12,13)$. These urinary apo(a) fragments, which are generated from the $\mathrm{NH}_{2}$-terminal portion of the tandem array of $\mathrm{K} 4$ repeats of apo(a), have been detected in all subjects examined to date, even those individuals who have no immunodetectable apo(a) in plasma (13). The amount of apo(a) fragments in urine is proportional to plasma levels of $\operatorname{Lp}(\mathrm{a})$. Injection of the urinary apo(a) fragments, but not intact Lp(a), into the circulation of mice results in excretion of apo(a) fragments of similar size in urine. These observations suggest that the apo(a) fragments in human urine may be derived from apo(a) fragments circulating in plasma, rather than from intact $\mathrm{Lp}(\mathrm{a})$.

In this paper, we demonstrate that fragments of apo(a) circulate in human plasma that are not covalently attached to apo-B100 and provide evidence that these apo(a) fragments 
are the likely source of the apo(a) immunoreactive fragments found in human urine.

\section{Methods}

Separation of lipoprotein-associated and "free" apo(a) in human plasma. Plasma was isolated from venous blood collected from subjects $A$ and $B$ in $10-\mathrm{ml}$ vacutainer tubes containing $117 \mu \mathrm{l}$ of $15 \%$ (wt/ vol) $\mathrm{Na}_{2}$ EDTA. Subject A was a 32-yr-old healthy Caucasian individual with apo(a) isoforms $\mathrm{K}_{29} /$ null and a plasma $\mathrm{Lp}$ (a) level of $0.5 \mathrm{mg} /$ dl. Subject B was a 32-yr-old Caucasian man with apo(a) isoforms $\mathrm{K} 4_{21} / \mathrm{K} 4_{22}$ and a plasma $\mathrm{Lp}(\mathrm{a})$ level of $20 \mathrm{mg} / \mathrm{dl}$. The size of the apo(a) isoforms was determined by immunoblot analysis after size-fractionation of plasma proteins on $2 \%$ SDS-agarose gel, as described (7). In the first series of experiments, a total of $500 \mu$ l of plasma was adjusted to a density of $1.215 \mathrm{grams} / \mathrm{ml}$ with potassium bromide in a final volume of $3.1 \mathrm{ml}$ and subjected to ultracentrifugation at $85,000 \mathrm{rpm}$ $(307,000 \mathrm{~g})$ for $17 \mathrm{~h}$ in a TLA 100.3 rotor on a TL-100 bench top ultracentrifuge (Beckman Instruments, Fullerton, CA). The top fraction $(150 \mu \mathrm{l})$ and the bottom fraction $(500 \mu \mathrm{l})$ were isolated and dialyzed against buffer $\mathrm{A}\left(150 \mathrm{mM} \mathrm{NaCl}, 0.2 \mathrm{mM} \mathrm{Na}_{2}\right.$ EDTA, pH 7.4). The top fraction was diluted to a final volume of $500 \mu \mathrm{l}$.

In parallel experiments the apo(a) associated with lipoproteins was separated from the so-called free apo(a). In this paper, "free" apo(a) refers to the apo(a) that is not covalently attached or strongly associated with apo-B100-containing lipoproteins. We developed a method to isolate the free apo(a) by incubating plasma with heparinSepharose beads to remove the apo(a) that is covalently bound to apo-B100. In the initial studies, six plasma samples from individuals with plasma $\mathrm{Lp}(\mathrm{a})$ levels ranging from 0.5 to $44.0 \mathrm{mg} / \mathrm{dl}$ were incubated with heparin-Sepharose beads at ratios ranging from 1:1 to 10:1 and the pattern of apo(a) immunoreactive material in the heparinunbound fraction was compared by immunoblot analysis. In four samples, the time interval of incubation was varied from 15 to 30 and to $90 \mathrm{~min}$. The banding pattern of free apo(a) did not change with variations in the ratio of heparin-Sepharose beads to plasma or with prolongation of the incubation time. The banding pattern also was not affected if the supernatant fluid was subjected to a second incubation with fresh beads. All experiments reported in this paper were performed by incubating $15 \mu \mathrm{l}$ of plasma from each subject with $50 \mu \mathrm{l}$ of Sepharose beads coated with heparin (Hi-trap ${ }^{\mathrm{TM}}$; Pharmacia, Piscataway, $\mathrm{NJ}$ ) in $45 \mu \mathrm{l}$ of buffer $\mathrm{B}$ (10 mM sodium phosphate, $\mathrm{pH} 7.0)$ for $30 \mathrm{~min}$ at room temperature. The samples were subjected to centrifugation at $11,000 \mathrm{~g}$ for $15 \mathrm{~s}$ and the supernatant fluid was collected. The beads were washed three times with buffer B and the heparinbound fraction was eluted with $50 \mu \mathrm{l}$ of buffer $\mathrm{C}(1 \mathrm{M} \mathrm{NaCl}, 10 \mathrm{mM}$ sodium phosphate, $\mathrm{pH}$ 7.0). After centrifugation, the eluted proteins were recovered in the supernate and diluted fivefold with buffer B. Samples were then analyzed by immunoblotting, as described (13).

Aliquots of total plasma, the heparin-bound, and heparin-unbound fractions were subjected to gel electrophoresis and immunoblotting. Briefly, proteins were size-fractionated on a $5 \%(\mathrm{wt} / \mathrm{vol})$ SDS-polyacrylamide gel for $35 \mathrm{~min}$ at $135 \mathrm{~V}$, transferred to nitrocellulose, and blotted with IgG-a5, an anti-apo(a) K4-type 1 and type 2-specific $\mathrm{mAb}$ (14). Detection was performed using the ECL chemiluminescence kit (Amersham, Arlington Heights, IL) and the filters were exposed for the indicated times to NEF 495 film (DuPont, Wilmington, DE).

Quantification of plasma $\operatorname{Lp}(a)$ and free apo(a) levels. Venous blood was collected from 42 healthy Caucasian individuals who all gave their informed consent. Venous blood was collected from two unrelated individuals with abetalipoproteinemia (kindly provided by Dr. Robert Hegele, University of Toronto, Canada). Venous blood was also collected from mice expressing a human apo(a) cDNA containing $17 \mathrm{~K} 4$ repeats and the human apo-B100 gene $(15,16)$, as well as a male cynomolgus monkey (kindly provided by Dr. R. Ramharack and Dr. R. Newton, Parke-Davis, Ann Arbor, MI) and 9 unre- lated baboons (17). The blood was maintained at $4^{\circ} \mathrm{C}$ until the plasma was isolated (always within $4 \mathrm{~h}$ ) and then aliquots were stored at $-80^{\circ} \mathrm{C}$. Plasma Lp(a) levels were determined by ELISA exactly as described (14) within 1 mo of collection. In this assay, IgG-a6, which recognizes the K4-type 2, and IgG-a40, which recognizes the K4-type 9 repeat, were used as the capture and detecting mAbs, respectively. The values are given for the protein mass of $L p(a)$ and should be multiplied by 2.76 to convert to total $L p(a)$ mass (14). We measured baboon plasma Lp(a) levels using the same ELISA assay calibrated with baboon plasma and using baboon plasma as quality controls. To quantitate the apo(a) in the supernatant fluid after subjecting the plasma to heparin chromatography, IgG-a5, which binds the type 1 and type $2 \mathrm{~K} 4$ repeats, rather than IgG-a40, was used as the detecting antibody in the ELISA assay (since the epitope for IgG-a40 is not present in the fragments). Unfortunately no anti-apo(a) antibodies are available that react with only a single epitope in the apo(a) fragments and thus measure apo(a) mass independent of the number of $\mathrm{K} 4$ repeats. The ELISA system used to measure the free apo(a) was calibrated to measure $\mathrm{Lp}(\mathrm{a})$ protein mass so the relative, not absolute, immunoreactivity of the free apo(a) is quantitated. No signal was obtained in the heparin-unbound fraction when anti-apoB or IgG-a40 was used as a detecting antibody, thus confirming that the heparin-unbound fraction did not contain any $\operatorname{Lp}(\mathrm{a})$. To validate the assay, plasma samples from 10 unrelated individuals with a wide range in plasma $\mathrm{Lp}(\mathrm{a})$ levels (from 0.4 to $44 \mathrm{mg} / \mathrm{dl}$ ) stored at $4^{\circ} \mathrm{C}$ were subjected to heparin-fractionation twice and the free apo(a) levels were quantitated in two different assays 7 wk apart and the correlation coefficient was 0.98 . The values for free apo(a) were multiplied by four to correct for the dilution of the samples with buffer B.

Unless otherwise indicated, all experiments were performed on plasma samples stored at $4^{\circ} \mathrm{C}$ from 1 to $24 \mathrm{~h}$ after collection or stored at $-80^{\circ} \mathrm{C}$ for $<6 \mathrm{mo}$.

Immunoblot analysis and quantification of urinary apo(a). Urine samples from humans and monkeys were concentrated using a Centriprep-30 and Centricon-30 concentrators (Amicon, Beverly, MA), and subjected to immunoblot analysis exactly as described (13). The 24-h urinary apo(a) excretion was quantitated using an ELISA assay exactly as described (13).

Analysis of apo(a) in culture medium from baboon hepatocytes. Baboon hepatocytes were grown in culture as described (18) and 72-h conditioned medium was collected, concentrated using a Centricon-30 filter, and subjected to heparin-Sepharose fractionation as described above.

Injection of purified human plasma free apo (a) in mice. A total of $50 \mathrm{ml}$ of plasma was collected from subject B. Aprotinin $(10 \mathrm{U} / \mathrm{ml})$, gentamicin $(0.08 \mathrm{mg} / \mathrm{ml})$, benzamidine $(1 \mathrm{mM})$, and PMSF $(1 \mathrm{mM})$ were added and the density was adjusted with $\mathrm{KBr}$ to 1.215 grams $/ \mathrm{ml}$. The sample was subjected to ultracentrifugation in a T875 rotor (Beckman) at 67,000 rpm for $24 \mathrm{~h}$. The bottom fraction $(30 \mathrm{ml})$ was isolated and dialyzed against buffer $\mathrm{A}$ with an overnight change against $30 \mathrm{mM} \mathrm{NaCl}, 0.04 \mathrm{mM} \mathrm{Na}_{2}$ EDTA, $10 \mathrm{mM}$ sodium phosphate, $\mathrm{pH}$ 7.2. The dialyzed sample was subjected to three sequential incubations with $5 \mathrm{ml}$ of heparin-coated Sepharose beads. The heparinunbound fraction was diluted threefold with buffer $\mathrm{A}$ and passed over the IgG-a6 immunoaffinity column, as described (13). Apo(a) fragments were eluted using $100 \mathrm{mM}$ triethylamine, $\mathrm{pH} 11.5$, and the first 2-ml fraction was collected in a tube containing $100 \mu \mathrm{l}$ of $1 \mathrm{M}$ sodium phosphate buffer, pH 6.8. BSA (Sigma, St. Louis, MO) was added to a final concentration of $1 \mathrm{mg} / \mathrm{ml}$ and the sample was dialyzed for $20 \mathrm{~h}$ against $150 \mathrm{mM} \mathrm{NaCl}$. The sample was concentrated 10-fold using a Centricon-30 filter and $130 \mu \mathrm{l}$ of the concentrated material was injected intravenously into two $(129 \times \mathrm{SJL})_{\mathrm{F} 1}$ female mice weighing 21 grams. Blood was collected by retroorbital puncture after $1 \mathrm{~min}, 5 \mathrm{~h}, 10 \mathrm{~h}$, and $20 \mathrm{~h}$. After the first blood collection, the mice were housed individually in metabolic cages and given $10 \%(\mathrm{wt} / \mathrm{vol})$ sucrose to drink. Urine samples were collected in chilled containers at the indicated time points. Urine samples were concentrated with a Microcon-30 filter and a total of $10 \%$ of the urine collection and $1 \mu \mathrm{l}$ 
of plasma were subjected to immunoblot analysis, as described above. Detection was performed using IgG-a5 conjugated to horseradish peroxidase (15).

\section{Results}

Both full-length apo(a) and truncated apo(a) fragments are present in human plasma. To determine if apo(a) fragments are present in human plasma, plasma samples from an individual with low (subject A) and high (subject B) plasma levels of $\mathrm{Lp}$ (a) were adjusted to a density of $1.215 \mathrm{grams} / \mathrm{ml}$ and subjected to ultracentrifugation. [Subject A has apo(a) isoforms of $\mathrm{K} 4_{29} /$ null and a plasma $\mathrm{Lp}(\mathrm{a})$ level of $0.5 \mathrm{mg} / \mathrm{dl}$ and subject $\mathrm{B}$ has apo(a) isoforms of $\mathrm{K} 4_{21} / \mathrm{K} 4_{22}$ and a plasma $\mathrm{Lp}(\mathrm{a})$ level of $20 \mathrm{mg} / \mathrm{dl}$.] The operational definition of a null allele in this paper is an apo(a) allele that is associated with $<0.1 \mathrm{mg} / \mathrm{dl} \mathrm{Lp(a),}$ which is the lower limit of detection in our immunoblotting assay (19). Aliquots of total plasma (lanes 1 and 7), the top (lanes 2 and 8 ), and bottom fractions (lanes 3 and 9 ) were subjected to immunoblot analysis using IgG-a5 (Fig. $1 A$ ), an mAb directed against the type 1 and type $2 \mathrm{~K} 4$ repeats of apo(a) (Fig. 1, bottom). To better visualize the complement of apo(a) immunoreactive fragments, a fivefold greater volume of the bottom fraction was loaded onto the gel. Immunoreactive proteins of the same size as the full-length apo(a) isoforms were detected in the top fraction in subject $A$, and in both the top and bottom fractions of subject B. Multiple smaller bands that ranged in size from $\sim 125$ to $360 \mathrm{kD}$ were seen in the bottom fractions of both subjects (lanes 3 and 9) that were not all visible in the untreated plasma on this exposure (lanes 1 and 7). Bands of identical sizes were seen in untreated plasma (lanes 1 and 7) on a longer exposure of the gel (data not shown).

To quantitate the relative proportion of apo(a) that circulates unattached to LDL in plasma, a method was developed to separate the apo(a) that is bound to LDL from the so-called free apo(a) by incubating the plasma with heparin-coated

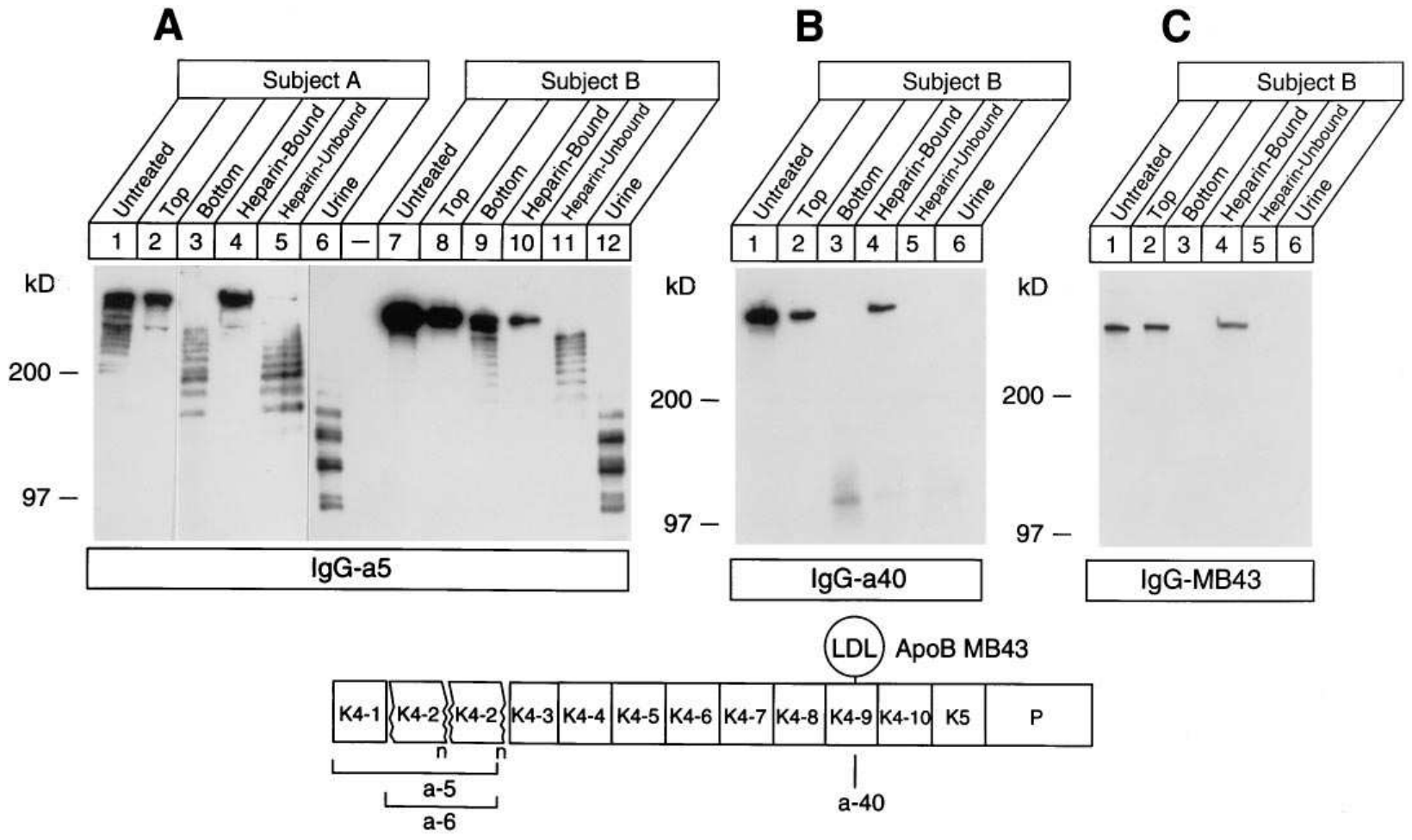

Figure 1. (A) Immunoblot analysis of plasma apo(a) K4-type 1 and 2 after ultracentrifugation and fractionation by heparin-Sepharose beads. Plasma and urine samples were collected from two healthy Caucasian individuals with a low $(0.5 \mathrm{mg} / \mathrm{dl} ;$ Subject A) and a high (20 mg/dl; Subject $B$ ) plasma level of $\mathrm{Lp}(\mathrm{a})$. Subjects A and B have apo(a) isoforms of $\mathrm{K} 4_{29} /$ null and $\mathrm{K} 4_{21} / \mathrm{K} 4_{22}$, respectively. A total of $500 \mu l$ of plasma was subjected to ultracentrifugation in a volume of $3.1 \mathrm{ml}$ at a density of $1.215 \mathrm{grams} / \mathrm{ml}$. The top $150-\mu \mathrm{l}$ fraction and the bottom 0.5 -ml fraction were collected and dialyzed against buffer $\mathrm{A}\left(150 \mathrm{mM} \mathrm{NaCl}, 0.2 \mathrm{mM} \mathrm{Na}_{2}\right.$ EDTA, $\left.\mathrm{pH} 7.4\right)$. The top fraction was diluted with buffer A to a final volume of $500 \mu \mathrm{l}$. In parallel experiments, $15 \mu \mathrm{l}$ of plasma from each individual was incubated for $30 \mathrm{~min}$ at room temperature with $50 \mu \mathrm{l}$ of heparin-coated Sepharose beads in $45 \mu \mathrm{l}$ of buffer B (10 mM sodium phosphate buffer, $\mathrm{pH}$ 7.0). After centrifugation, the top (heparin-unbound) fraction was collected. The pellet was washed three times with buffer B and resuspended in $50 \mu \mathrm{l}$ of buffer $\mathrm{C}(10 \mathrm{mM}$ phosphate buffer, $1 \mathrm{M} \mathrm{NaCl}$, pH 7.0$)$. The eluted proteins were diluted with buffer B to a final volume of $250 \mu$. The urine was concentrated 150-fold using Centriprep-30 and Centricon-30 concentrators. For subject A, a total of $0.75 \mu \mathrm{l}$ of plasma (lane 1), $1.25 \mu \mathrm{l}$ of the top fraction (lane 2), $1.25 \mu 1$ of the bottom fraction (lane 3 ), $11 \mu \mathrm{l}$ of the heparin-bound fraction (lane 4), $10 \mu \mathrm{l}$ of the heparin-unbound fraction (lane 5), and $1 \mu \mathrm{l}$ of concentrated urine (lane 6 ) was reduced and size-fractionated on a 5\%(wt/vol) SDS-polyacrylamide gel for $35 \mathrm{~min}$ at $4^{\circ} \mathrm{C}$, transferred to a nitrocellulose filter and blotted with IgG-a5, which recognizes the apo(a) K4-type 1 and 2 repeats. To account for the difference in plasma Lp(a) levels between subjects A and B, the amount of plasma, top, and heparin-bound fractions was 40-fold less for subject B than for subject A, whereas the amount of proteins in the bottom and the heparin-unbound fractions was 10-fold less. Duplicate blots using samples from subject B were subjected to immunoblot analysis using IgG-a40, an anti-apo(a) K4-type $9 \mathrm{mAb}(B)$, and IgG-MB43, an anti-apo-B100 specific $\mathrm{mAb}(C)$. Detection was performed using the ECL chemiluminescence kit. The filters were exposed for $8 \mathrm{~min}(A), 4 \mathrm{~min}(B)$, and $15 \mathrm{~s}(C)$. (Bottom) Location of the epitopes recognized by the $\mathrm{mAbs}$ used in the analysis. 
Sepharose beads, as described in Methods. Aliquots of the high-salt eluate from the beads (Fig. $1 A$, lanes 4 and 10) and the supernatant fluid (lanes 5 and 11) were analyzed by immunoblotting. For both subjects, the immunodetectable apo(a) in the heparin-bound fraction (lanes 4 and 10) was similar in size to the full-length apo(a) isoforms detected in the untreated plasma (lanes 1 and 7) and the top fraction (lanes 2 and 8). In both samples, only a trace amount of the full-length immunoreactive apo(a) was detected in the heparin-unbound fraction (lanes 5 and 11). A series of smaller polypeptides was visible in the heparin-unbound fractions that were similar in size to those detected in the bottom fraction (lanes 3 and 9). In subject $\mathrm{B}$, a significant amount of apo(a) was present in the bottom fraction (lane 9) that was not apparent in the heparinunbound fraction (lane 11), which is consistent with a portion of the apo(a) being associated with another heparin-binding protein or with apo-B100 in a lipid-poor particle. The relative amount of apo(a) present in the bottom fraction was very small since fivefold more of the bottom than top fraction was loaded onto the gel. In subject A, a band of lower intensity was detected in the untreated plasma (lane 1), and in the top (lane 2), the heparin-bound (lane 3), and the heparin-unbound fractions (lane 5). This band was of the same apparent molecular mass as the largest band in the bottom fraction. The nature of this band has not been determined.

The apo(a) immunoreactive fragments in the bottom and the heparin-unbound fractions of both plasma samples were similar in size to some of the larger apo(a) immunoreactive fragments detected in urine from the same subjects (lanes 6 and 12). The size differences between apo(a) fragments was $\sim 25-30 \mathrm{kD}$, which is the estimated size of a single type $2 \mathrm{~K} 4$ repeat (20). The banding pattern of the polypeptides did not

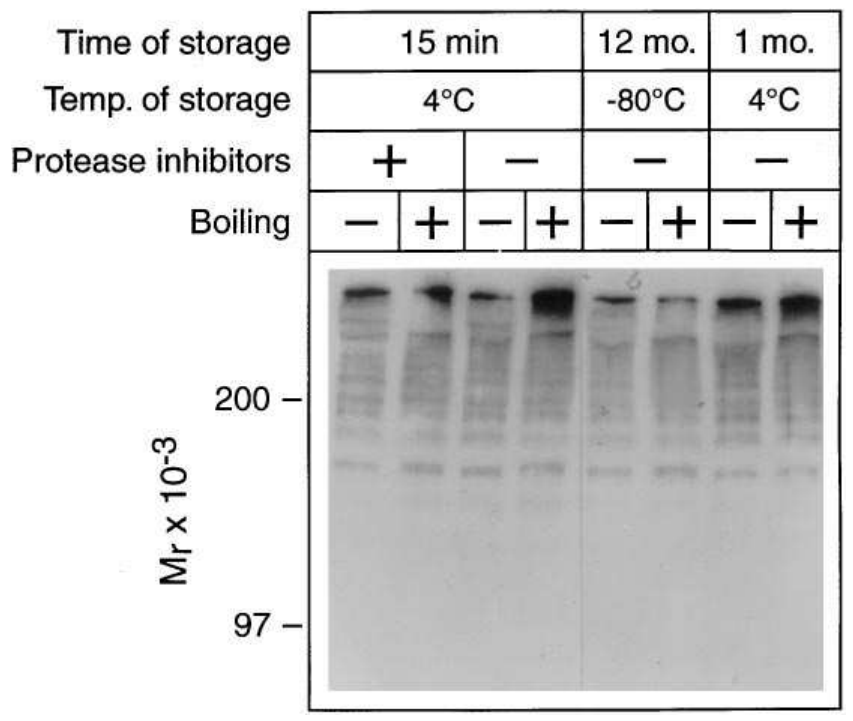

Figure 2. Effect of storage, boiling, and protease inhibitors on plasma apo(a). Plasma was collected from subject $\mathrm{C}$, a healthy Caucasian individual who has a plasma $\mathrm{Lp}$ (a) level of $0.7 \mathrm{mg} / \mathrm{dl}$ and is homozygous for apo(a) $K 4_{29}$. A cocktail of protease inhibitors containing aprotinin (final concentration $10 \mathrm{U} / \mathrm{ml})$, gentamycin $(80 \mu \mathrm{g} / \mathrm{ml})$, benzamidine $(1 \mathrm{mM})$, and PMSF $(1 \mathrm{mM})$ was added to plasma where indicated. Samples were boiled for $5 \mathrm{~min}$ where indicated. A total of $0.75 \mu \mathrm{l}$ of plasma was analyzed by immunoblotting using IgG-a5, as described in Fig. 1. Filter was exposed to film for $4 \mathrm{~min}$. change if the ratio of heparin beads to plasma was increased, if the incubation time was prolonged, or if the supernatant fluid was subjected to serial incubation with fresh beads (data not shown).

To determine if the truncated forms of apo(a) in plasma contained the K4-type 9 repeat, which is the $\mathrm{K} 4$ repeat with the cysteine residue that cross-links apo(a) to the apo-B100 of LDL, the same samples from subject B were subjected to immunoblotting with IgG-a40 (Fig. 1 B), an anti-apo(a) K4-type 9 specific $\mathrm{mAb}$ (14). No apo(a) immunoreactive material was identified in the bottom (lane 3 ) or heparin-unbound fractions (lane 5). A trace amount of the full-length apo(a) isoform was visible in the bottom fraction after prolonged exposure (data not shown). A faint band of $\sim 100 \mathrm{kD}$ was seen in the bottom fraction and heparin-bound fraction of all plasma samples analyzed. The intensity of this band did not vary with the plasma level of $\mathrm{Lp}(\mathrm{a})$ and so was attributed to a cross-reacting protein.

To demonstrate that the free apo(a) in plasma circulates independent of apo-B100, immunoblot analysis was also performed on the same samples from subject B using IgG-MB43 (Fig. 1 C), an anti-apo-B100 mAb (21). No apo-B100 was identified in the bottom (lane 3 ) or heparin-unbound fraction (lane 5) except on a prolonged exposure when a trace amount of apo-B100 was visible in the bottom fraction (data not shown). This is consistent with a trace amount of a lipid-poor
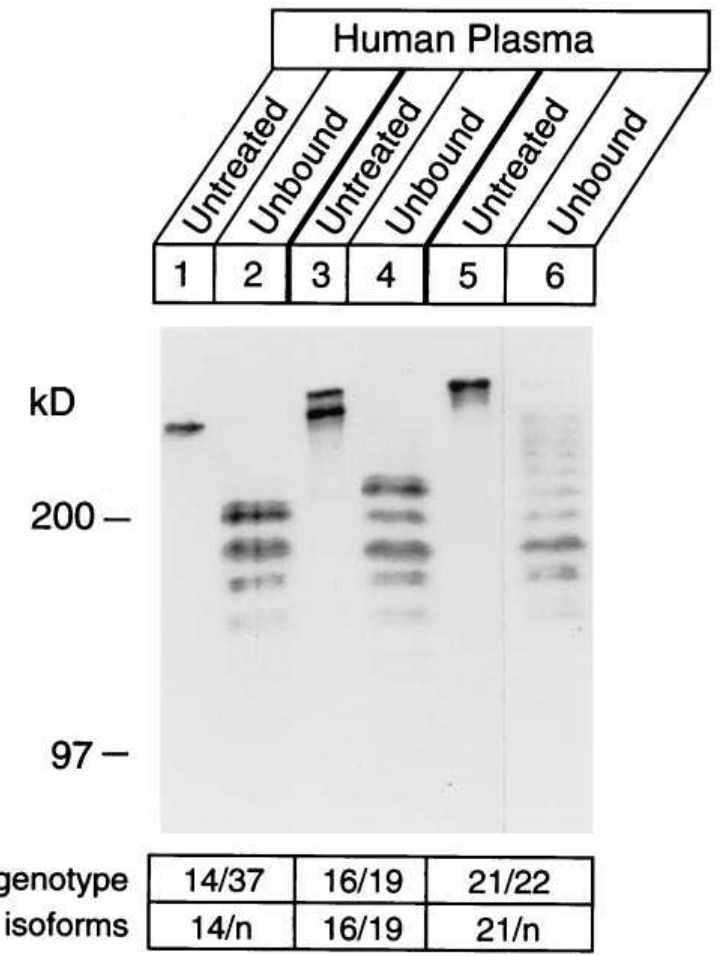

Figure 3. Relationship between the sizes of the apo(a) isoforms and the free apo(a) in plasma. Blood was collected from three healthy individuals and the plasma samples were incubated with heparincoated beads to remove the $\mathrm{Lp}$ (a), as described in Fig. 1. A total of 1 $\mu \mathrm{l}$ of a 100 -fold diluted plasma sample and $5 \mu \mathrm{l}$ of the supernate was analyzed by immunoblotting using IgG-a5. The filter was exposed to film for $4 \mathrm{~min}$. The number of K4 repeats in the apo(a) gene was determined by pulsed-field gel electrophoresis of high molecular mass genomic DNA and genomic blotting, as described (7). 
apo(a)-apo-B100 complex being present in the bottom fraction, as has been seen previously in individuals with abetalipoproteinemia (22). Taken together, these results indicate that a fraction of the apo(a) immunoreactive material in plasma circulates unattached to lipoproteins [although a noncovalent bond between the apo(a) fragments and LDL cannot be formally ruled out]. This free apo(a) consists of a trace amount of full-length apo(a) and a series of fragments of discrete sizes that contain the highly reiterated K4-type 2 repeats, but not the apo(a) K4-type 9 repeat. The size differences between the fragments approximates the size of a single K4-type 2 repeat, which suggests that the apo(a) fragments of different sizes vary in the number of K4-type 2 repeats.

Stability of apo(a) fragments in plasma. To examine whether the apo(a) fragments identified in human plasma are proteolytic products that arise from $\mathrm{Lp}$ (a) during isolation, plasma from subject $\mathrm{C}$, a 36-yr-old healthy Caucasian individual with an apo(a) genotype $\mathrm{K} 4_{29} / \mathrm{K} 4_{29}$ and a plasma Lp(a) level of 0.7 $\mathrm{mg} / \mathrm{dl}$, was subjected to electrophoresis within $15 \mathrm{~min}$ of isolation in the presence or absence of protease inhibitors. The banding pattern did not change significantly whether the samples were boiled or stored for $1 \mathrm{mo}$ at $4^{\circ} \mathrm{C}$ or $1 \mathrm{yr}$ at $-80^{\circ} \mathrm{C}$ (Fig. 2). No differences were observed if the analysis was performed using serum (data not shown). It is still possible that the apo(a) fragments were generated during sample collection or processing, although the analysis of plasma samples from mice expressing both a human apo(a) and a human apo-B100 transgenes argues strongly against this possibility (see below).

Relationship between the size of the apo(a) fragments and apo (a) isoforms. To determine if the apparent molecular mass of the fragments varied between individuals with apo(a) isoforms of different sizes, plasma samples from a series of individuals were subjected to incubation with heparin-Sepharose beads. Aliquots of untreated plasma and the supernatant fluid were analyzed by immunoblotting (Fig. 3). The first individual had a single apo(a) isoform visible in plasma that contained 14 $\mathrm{K} 4$ repeats and had a molecular mass of $\sim 420 \mathrm{kD}$ (lane 1 ). Four major fragments of $\sim 135,160,185$, and $215 \mathrm{kD}$ were detected in the heparin-unbound fraction (lane 2). The second individual had two plasma apo(a) isoforms of $\sim 560$ and 480 $\mathrm{kD}$ in the plasma (lane 3). The heparin-unbound fraction from this subject contained the same apo(a) fragments that were seen in subject 1 and an additional larger protein of $\sim 245 \mathrm{kD}$ (lane 4). A longer exposure also revealed bands of $\sim 270,300$, and $330 \mathrm{kD}$ (data not shown). A third individual, who had a single isoform of $\sim 600 \mathrm{kD}$ (lane 5), had a series of apo(a) fragments $(\sim 345$ and $380 \mathrm{kD})$ that were larger in size than any of those seen in the other two individuals (lane 6 ). Thus, in all three individuals, there was a direct relationship between the size of the apo(a) isoforms and the size of the largest fragments

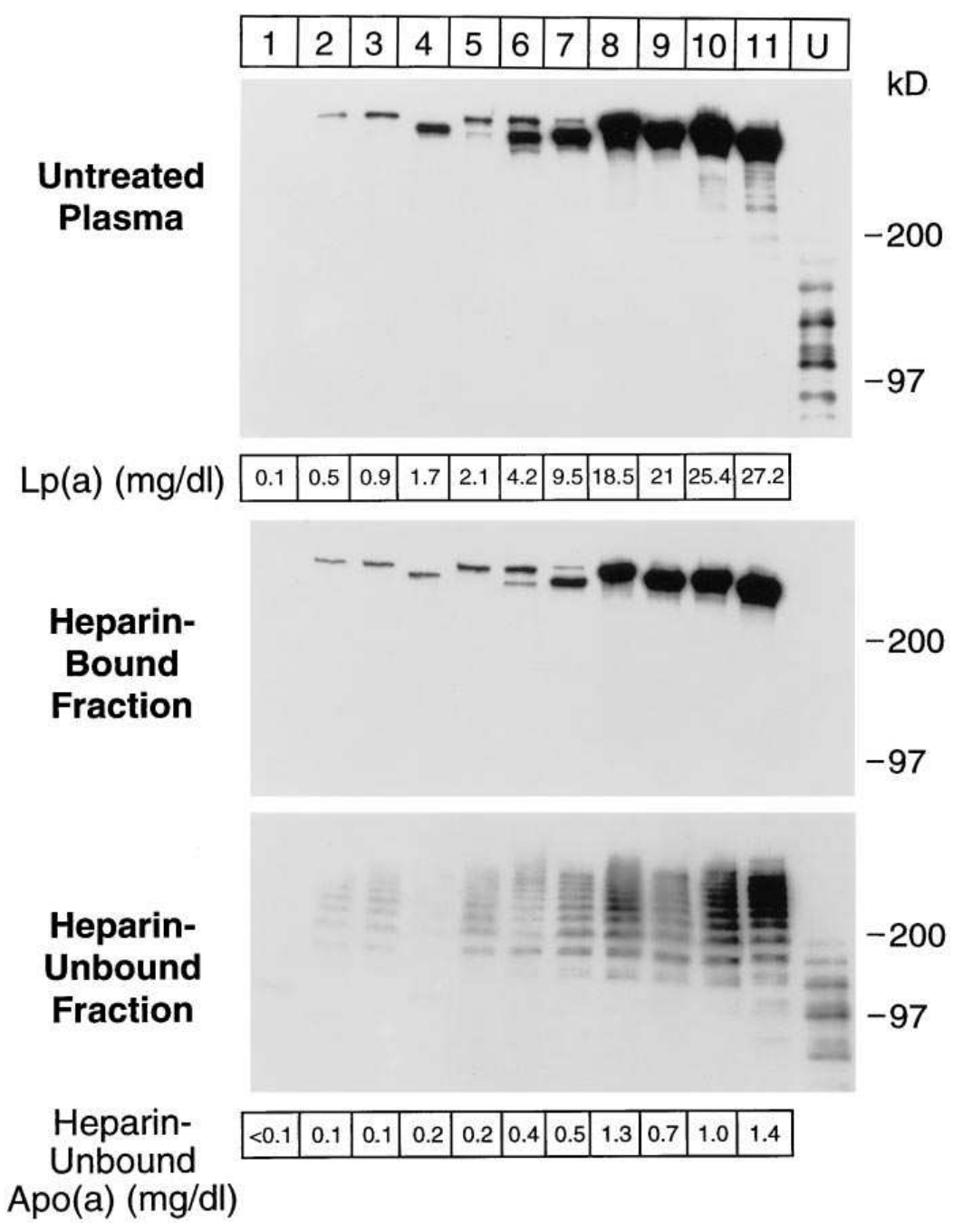

Figure 4. Immunoblot analysis of untreated, heparin-bound, and heparin-unbound apo(a) in plasma. Plasma samples from 11 unrelated individuals and a sample of 100-fold concentrated urine from subject 2 were subjected to heparin-Sepharose fractionation as described in Fig. 1. A total of $0.25 \mu$ l of plasma (top), $5 \mu \mathrm{l}$ of heparin-bound fraction (middle), and $5 \mu \mathrm{l}$ of heparin-unbound fraction (bottom) was analyzed by immunoblotting using IgG-a5, as described in Fig. 1. The filters were exposed to film for $16 \mathrm{~min}$ (top and bottom) and 4 min (middle). 


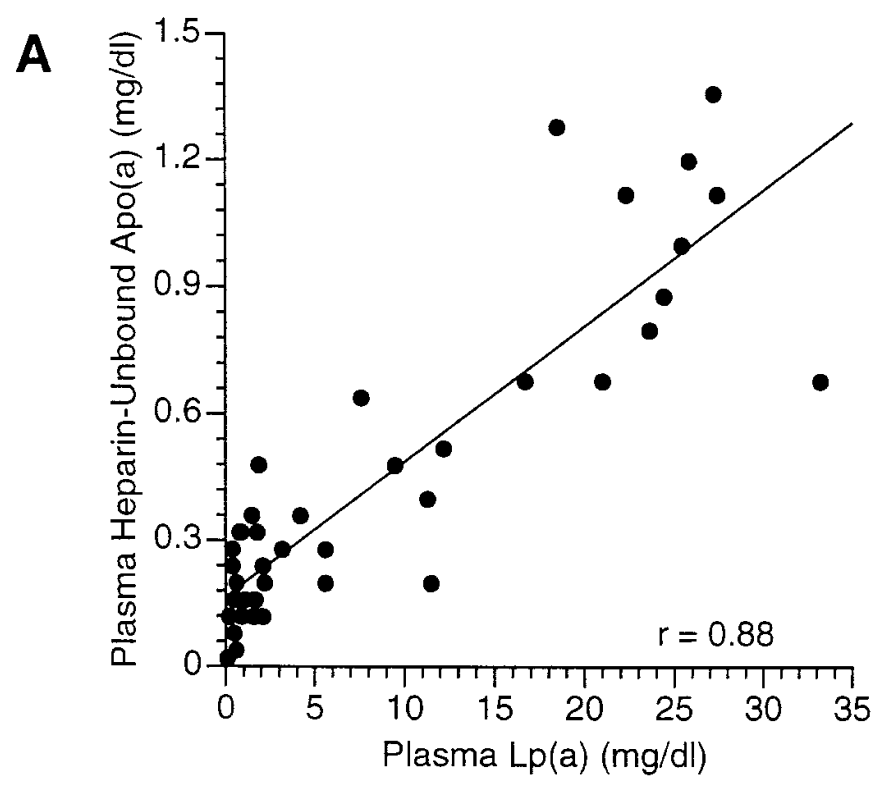

B

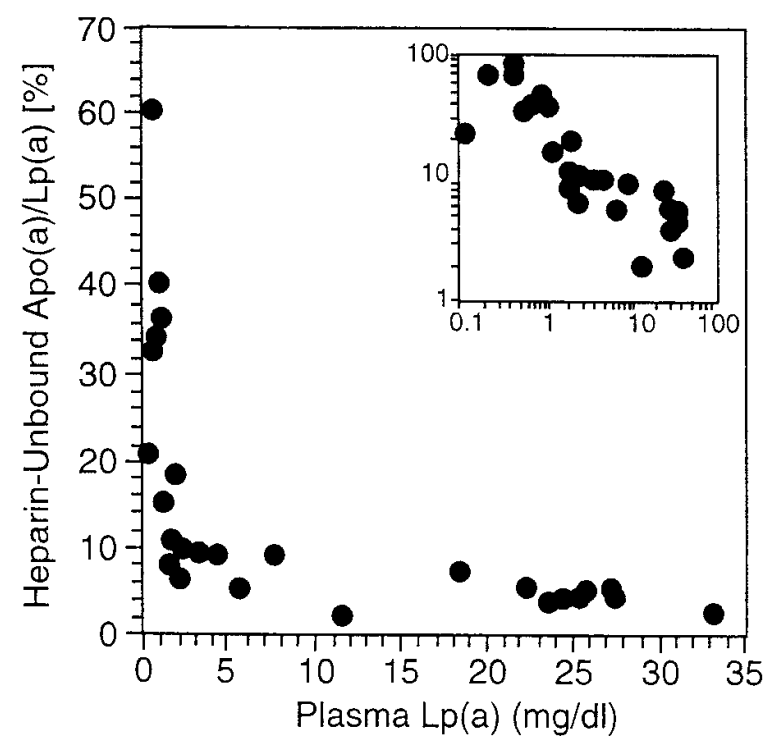

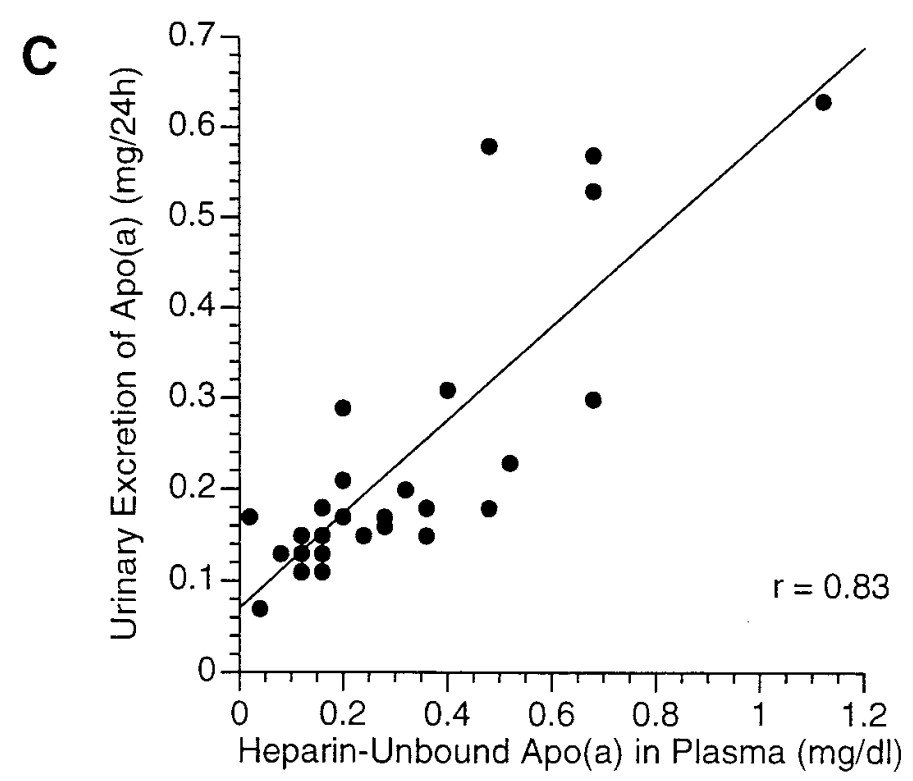

Figure 5. (A) Plasma levels of $\mathrm{Lp}(\mathrm{a})$ and free apo(a) in Caucasian individuals. Plasma was collected from 42 healthy individuals and the free apo(a) was isolated from each sample using heparin-Sepharose beads, as described in the legend to Fig. 1. The amount of Lp(a) and free apo(a) in the samples was quantitated using a sandwich ELISA assay, as described in Methods. The plasma Lp(a) level is given on the $x$ axis, and the amount of free apo(a) on the $y$ axis. (B) Relationship between plasma Lp(a) levels and the ratio of free apo(a) to Lp(a) in plasma. Plasma Lp(a) levels and heparin-unbound apo(a) were quantified as described in Methods. (Inset) Same data plotted on a $\log / \log$ scales. (C) Relationship between the amount of free apo(a) in the plasma and the 24-h urinary excretion of apo(a). 20-h urine samples were collected from 27 Caucasian individuals and urinary apo(a) and plasma-free apo(a) were quantitated as described in Methods.

detected in plasma. The largest apo(a) fragments detected in the heparin-unbound fraction were $\sim 200 \mathrm{kD}$ smaller than the largest apo(a) isoform.

Relationship between the amount of total plasma apo(a), heparin-bound, and heparin-unbound apo(a). Immunoblot analysis of apo(a) in untreated plasma, heparin-bound, and heparin-unbound fractions was performed in plasma samples from 11 selected healthy Caucasian individuals whose plasma levels of $\mathrm{Lp}$ (a) ranged from 0.1 to $27.2 \mathrm{mg} / \mathrm{dl}$ (Fig. 4). The intensity of the apo(a) bands in the plasma and heparin-bound fraction correlated with plasma Lp(a) level (Fig. 4, top and middle).
Shown in the bottom panel is the immunoblot analysis of the heparin-unbound fraction. A similar, though nonidentical, pattern of bands was seen in the plasma samples of all individuals examined. The intensity of the bands tended to increase in proportion to the plasma levels of $\mathrm{Lp}(\mathrm{a})$.

To quantitate the relationship between the plasma level of $\mathrm{Lp}(\mathrm{a})$ and the plasma level of free apo(a), the levels were determined in 42 healthy Caucasian individuals ( 23 males and 19 females) using an ELISA assay, as described in Methods. A direct relationship was observed between the plasma concentrations of $\mathrm{Lp}$ (a) and free apo(a) (Fig. $5 A$ ), as expected based on 


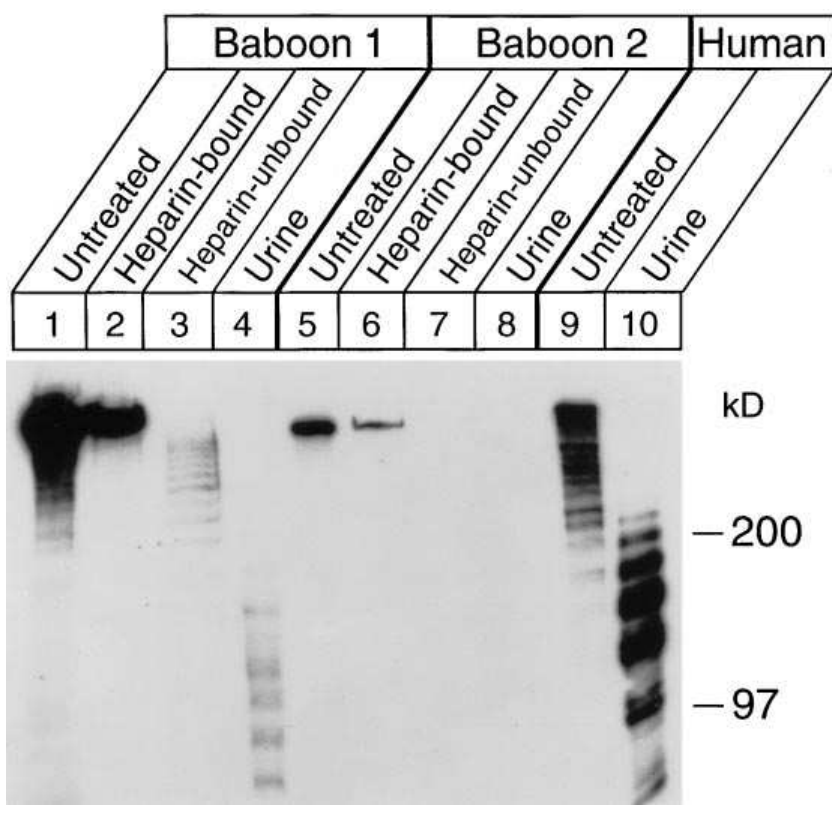

Figure 6. Immunoblot analysis of apo(a) in untreated, heparinbound, and heparin-unbound plasma from two baboons. Plasma was isolated from nine baboons and subjected to heparin-Sepharose fractionation as described in Fig. 1. The plasma of eight of the nine baboons had a banding pattern similar to baboon 1 and had a series of apo(a) fragments in the heparin-unbound fraction (lane 3) and urine (lane 4) that were similar in size to those found in humans (subject $\mathrm{C}$, lanes 9 and 10). In one of the baboons, baboon 2, no apo(a) immunoreactive fragments were identified in either plasma or urine (lanes 7 and 8 ).

the immunoblot analysis of the plasma and heparin-unbound fraction (Fig. 4). The levels of free apo(a) ranged from 0.02 to $1.36 \mathrm{mg} / \mathrm{dl}$. The relationship between the proportion of apo(a) that circulates free in plasma and the level of plasma $\mathrm{Lp}(\mathrm{a})$ was also examined (Fig. $5 \mathrm{~B}$ ). The proportion of free apo(a) in plasma differed depending on the plasma level of $\mathrm{Lp}(\mathrm{a})$. In the subset of individuals with very low plasma $\mathrm{Lp}(\mathrm{a})$ levels (i.e., $<1 \mathrm{mg} / \mathrm{dl}$ ), $\sim 20-60 \%$ of the apo(a) was not covalently bound to lipoproteins. In contrast, all individuals with plasma $\mathrm{Lp}(\mathrm{a})$ levels $>2 \mathrm{mg} / \mathrm{dl}$ had $<10 \%$ of their apo(a) in the heparinunbound fraction. The relationship between the plasma Lp(a) levels and the proportion of apo(a) that circulated was linear when the data were replotted using a logarithmic scale (Fig. 5 $B$, inset).

We next examined the relationship between the plasma free apo(a) level and the amount of apo(a) excreted into the urine in a 24-h period in 27 individuals with normal renal function, as assessed by creatinine clearance, and no proteinuria. The level of free apo(a) fragments in plasma was directly related to the amount of apo(a) excreted into the urine during a 24-h period $(r=0.83$ ) (Fig. $5 C$ ). The close correlation between the amount of free apo(a) in plasma and the urinary apo(a) suggested a precursor-product relationship.

Apo(a) fragments are present in baboon plasma and urine but absent from the conditioned media of primary baboon hepatocytes. To determine if apo(a) fragments were present in the plasma of another species that synthesizes apo(a), we immunologically examined the plasma and urine from nine unrelated baboons, which had plasma Lp(a) levels that ranged

from 0.1 to $17.4 \mathrm{mg} / \mathrm{dl}$. The immunoblot analysis of plasma from two representative baboons is shown in Fig. 6. Seven of the eight baboons had a series of apo(a) immunoreactive fragments present in both the heparin-unbound fraction (lane 3) and urine (lane 4) that were similar in size to those seen in humans (lanes 9 and 10). The baboon that had the lowest plasma level of $\mathrm{Lp}(\mathrm{a})(0.1 \mathrm{mg} / \mathrm{dl})$ had no apo(a) immunoreactive material either in the plasma or the urine (lanes 7 and 8 ). To date we have analyzed the plasma and urine of 100 humans for the presence of apo(a) fragments and no human sample has been identified that does not have apo(a) fragments (data not shown). A similar analysis was performed using plasma and urine from a cynomolgus monkey (23) (samples kindly provided by R. Ramharack and R. Newton) and the results were similar to those observed in the baboons (data not shown).

To determine if the apo(a) fragments in the plasma are secreted by the liver, plasma and conditioned media from primary cultures of hepatocytes from a baboon with a plasma level of $\mathrm{Lp}(\mathrm{a})$ of $16.6 \mathrm{mg} / \mathrm{dl}$ were subjected to Sepharose-heparin fractionation and analyzed by immunoblotting (Fig. 7). The plasma contained a series of apo(a) fragments (lanes 1 and 3) similar in size to those seen in humans. Full-length apo(a) was present in both the heparin-bound and the heparin-unbound fractions of the media. The presence of fulllength apo(a) in the heparin-unbound fraction is due to the fact that excess LDL was not added to the media. No apo(a) fragments were present in the heparin-unbound fraction in the conditioned media (lane 6), even after a very long exposure. Since the apo(a) that circulates in plasma is formed in the liver (24), these results suggest that the apo(a) fragments present in the plasma are not produced by the hepatocytes but are rather generated from circulating Lp(a) or full-length apo(a) that circulates unattached to LDL.

Apo-B100 is not required for the generation of the apo(a) fragments. To determine if apo-B100 is necessary for the generation of apo(a) fragments, plasma from two individuals who have abetalipoproteinemia (kindly provided by Dr. Robert Hegele) was subjected to Sepharose-heparin fractionation and
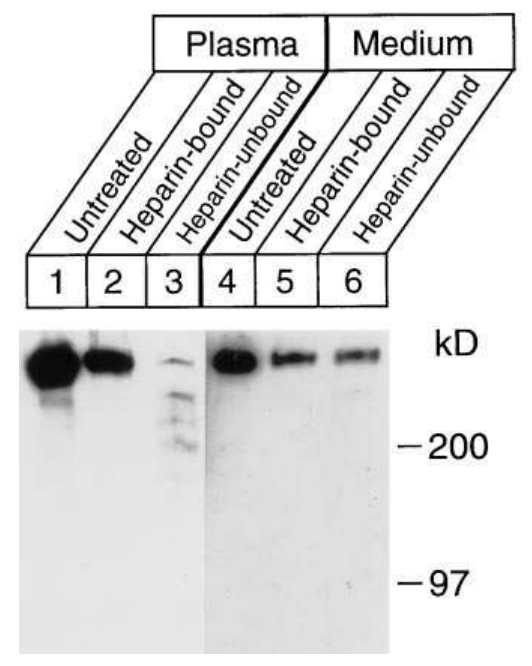

Figure 7. Immunoblot analysis of apo(a) in tissue culture medium from baboon hepatocytes. Plasma and 72-h conditioned medium from hepatocytes from the same baboon were collected. Plasma and 10 -fold concentrated medium were subjected to heparin-Sepharose fractionation as described in Fig. 1. The untreated and the heparin-bound and heparin-unbound media were further concentrated 10 -fold. A total of $0.25 \mu$ l of untreated material and $7.5 \mu \mathrm{l}$ of the heparin-unbound and heparin-bound fractions was analyzed by immunoblotting using IgG-a5. The filter was exposed for $30 \mathrm{~s}$ (lanes 1-3) and $30 \mathrm{~min}$ (lanes 4-6). 


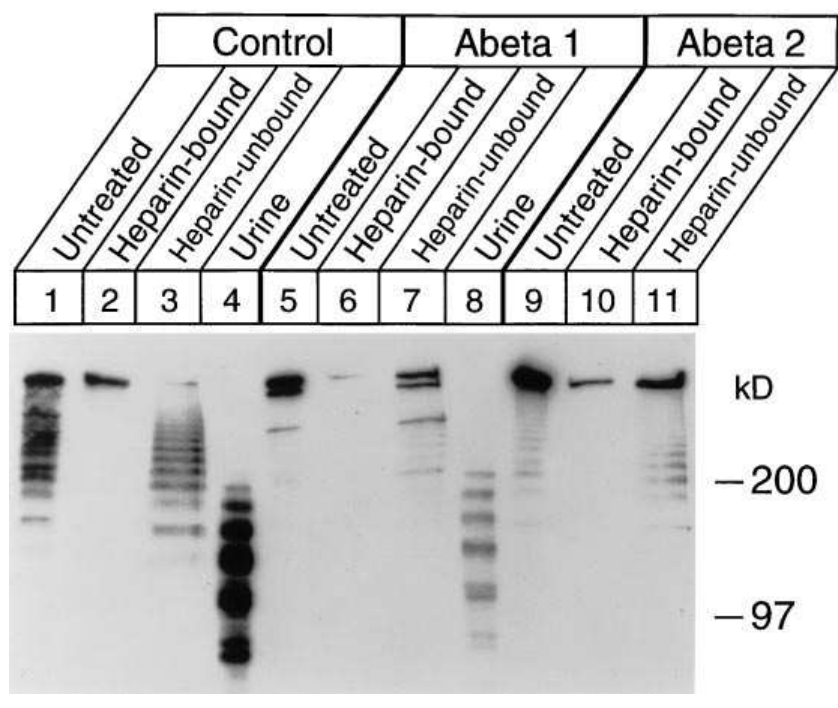

Figure 8. Immunoblot analysis of plasma and urine apo(a) in abetalipoproteinemia. Plasma was collected from two subjects with abetalipoproteinemia, who have a plasma $\mathrm{Lp}(\mathrm{a})$ level of 0.3 and $0.2 \mathrm{mg} / \mathrm{dl}$, respectively. Urine was available only from subject 1 . Samples from subject C served as controls. Plasma samples were subjected to heparin-Sepharose fractionation and to immunoblotting, as described in Fig. 1. The filter was exposed for $4 \mathrm{~min}$.

immunoblotting (Fig. 8). The plasma levels of $\mathrm{Lp}(\mathrm{a})$ in these individuals were 0.3 and $0.2 \mathrm{mg} / \mathrm{dl}$. Both individuals had apo(a) in the heparin-bound (lanes 6 and 10) and heparin-unbound (lanes 7 and 11) fractions. The samples were also subjected to size-fractionation on a nondenaturing gel (15) and in the heparin-unbound fraction, all of the full-length apo(a) comigrated with free apo(a). In contrast, the apo(a) in the heparin-bound fraction migrated a shorter distance in the gel, which is consistent with it being bound to apo-B100 or another heparin-binding protein (data not shown). Although no apo-B100 could be detected in the plasma or in the heparin-unbound fraction of either individual (data not shown), the level of plasma apoB100 may be below the detection limits of our immunoblotting method. Trace amounts of apo-B100 have been detected in the plasma of other individuals with abetalipoproteinemia (22). A series of smaller apo(a) fragments similar in size to those seen in the control subject (lane 3) was present in the heparinunbound fraction. The proportion of apo(a) circulating as free apo(a) was 9 and $38 \%$ in these two individuals, which was within the same range as seen in normal individuals with very low plasma Lp(a) levels (see Fig. 5 B). Apo(a) fragments were also detected in the urine (lane 8 ), which was available from only one of the subjects. Based on these studies we concluded that apo-B100 was probably not required for the generation of the apo(a) fragments in humans and also that very low to absent levels of plasma apo-B100 are not associated with an increase in the proportion of free apo(a).

Apo(a) fragments are not present in the plasma of apo(a) transgenic mice. In contrast to monkeys, baboons, and humans, mice do not have any immunodetectable apo(a) in their plasma (15). Transgenic mice expressing a human apo(a) cDNA driven by the mouse transferrin promoter (15) crossed with mice expressing the human apo-B100 gene (16) have $\mathrm{Lp}(\mathrm{a})$ in their plasma $(16,25)$. Plasma from these mice was

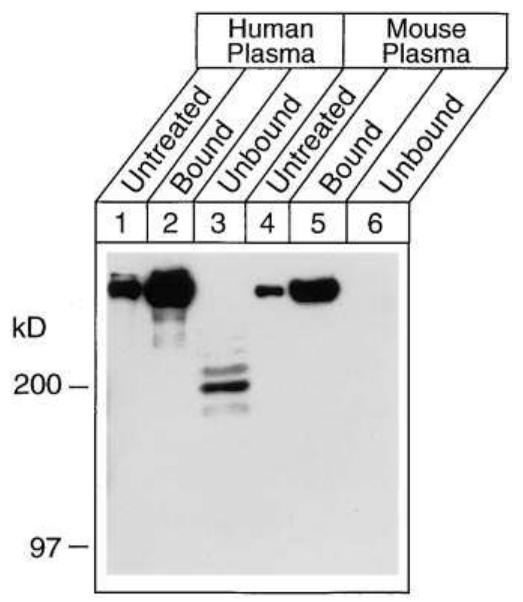

Figure 9. Immunoblot analysis of apo(a) in plasma from a mouse expressing both human apo(a) and apo-B100 transgenes. Plasma was collected from a healthy Caucasian individual with an apo(a) genotype apo(a) $K 4_{20}$ $K 4_{28}$ and a plasma $\mathrm{Lp}(\mathrm{a})$ level of $6.5 \mathrm{mg} /$ $\mathrm{dl}$ and from a transgenic mouse expressing both a human apo(a) cDNA with 17 $\mathrm{K} 4$ repeats and the human apo-B100 gene

and a plasma $\mathrm{Lp}$ (a) level of $\sim 8 \mathrm{mg} / \mathrm{dl}(15,16)$. The plasma samples were incubated with heparin-Sepharose beads as described in Fig. 1 and then a $2.5-\mu l$ aliquot of a 100 -fold diluted plasma, $7.5 \mu l$ of the heparin-bound fraction, and $2 \mu \mathrm{l}$ of the supernatant fluid were subjected to immunoblotting using horseradish peroxidase-conjugated IgG-a5, an $\mathrm{mAb}$ that recognizes the apo(a) K4-type 1 and 2 repeats. The filter was exposed to film for $8 \mathrm{~min}$.

subjected to incubation with heparin-Sepharose beads and the untreated, heparin-bound, and heparin-unbound fractions were analyzed by immunoblotting. In contrast to human plasma (Fig. 9, lanes 1-3) and monkey plasma, no apo(a) fragments were identified in the mouse plasma before (lane 4 ) or after (lanes 5 and 6 ) incubation with the heparin-coated Sepharose beads. The same experiment was performed using plasma from mice expressing the apo(a) but not the apo-B100 transgene, and mice expressing a 270-kb DNA fragment encompassing the entire apo(a) gene (Acquati, F., and R. Hammer, unpublished observation). No apo(a) fragments were detected in the heparin-unbound fraction in either of these lines of mice (data not shown). Mice, which do not synthesize apo(a), do not appear to have the machinery required to generate these apo(a) fragments. Moreover, the absence of the fragments in the transgenic mouse plasma is consistent with the apo(a) fragments in human and monkey plasma not being generated during the isolation or preparation of the plasma sample but rather being produced in vivo.

Finally, when plasma from apo(a) transgenic mice was mixed with human plasma (or serum), no increase in the amount of apo(a) fragments, either before or after incubation with heparin-Sepharose beads, was found on immunoblot analysis (data not shown).

Intravenous injection of human apo(a) fragments into mice results in excretion of smaller fragments into the urine. To investigate if the apo(a) fragments in human plasma could be the source of the apo(a) immunoreactive fragments in urine, two mice were injected intravenously with free apo(a) purified from human plasma. Plasma (Fig. $10 A$ ) and urine (Fig. $10 \mathrm{~B}$ ) were collected for immunoblot analysis of apo(a). Most of apo(a) fragments had been cleared from the mouse plasma after $5 \mathrm{~h}$. Over the same time period, a series of apo(a) fragments was easily detected in mouse urine. The apo(a) fragments in mouse urine were smaller in size than those injected into the mice and matched precisely the sizes of apo(a) fragments in human urine (Fig. $10 B$, lane 1). 


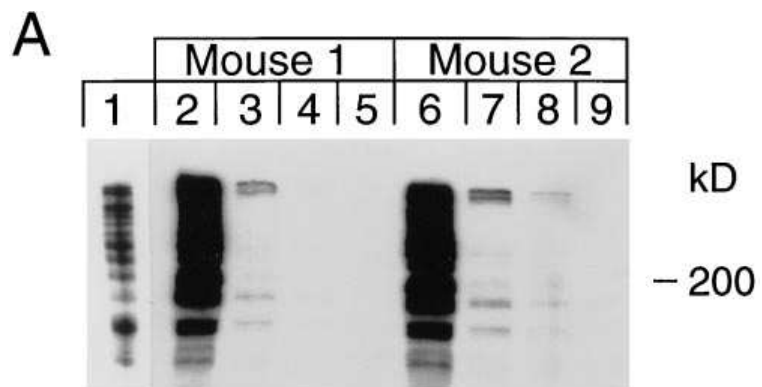

Time $\quad[1 / 60|5| 10|20| 1 / 60|5| 10|20|$

(h)

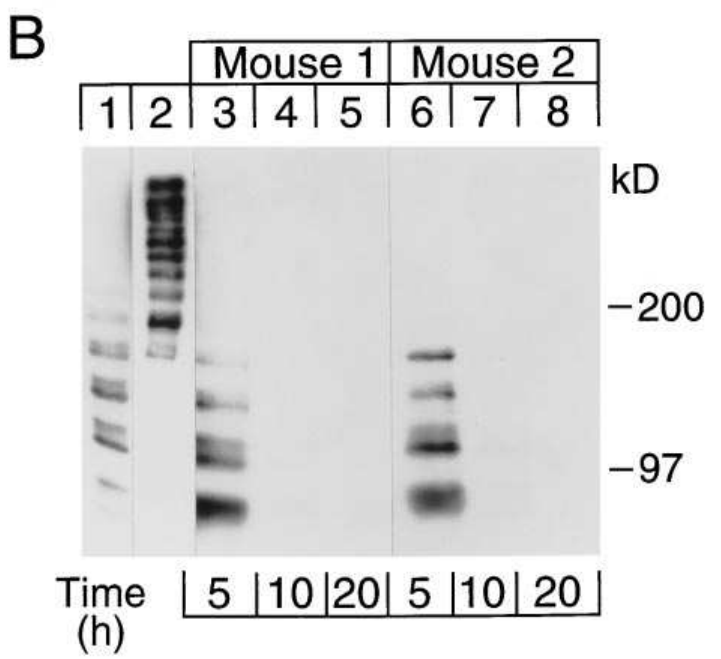

Figure 10. Immunoblot analysis of plasma and urinary apo(a) in two mice injected with free apo(a) purified from human plasma. Two (129 $\times \mathrm{SJL})_{\mathrm{F} 1}$ female mice were injected intravenously with $130 \mu \mathrm{l}$ of free apo(a) purified as described in Methods from $50 \mathrm{ml}$ of plasma from an individual with an apo(a) genotype $\operatorname{apo}(a) K 4_{21} / K 4_{22}$ and a plasma $\mathrm{Lp}$ (a) level of $22 \mathrm{mg} / \mathrm{dl}$. Blood and urine were collected at the indicated time points. A total of $1 \mu \mathrm{l}$ of plasma $(A)$ and $10 \%$ of the urine collection $(B)$ at each time point was subjected to immunoblot analysis as described in Fig. 1. A total of $0.1 \mu$ of the injected material ( $A$, lane 1 and $B$, lane 2 ) and $0.75 \mu$ l of 150 -fold concentrated human urine $(B$, lane 1$)$ were used as controls. Filters were exposed for $1 \mathrm{~min}$ $(A)$ and $8 \min (B)$.

\section{Discussion}

The major findings of this paper are that truncated forms of apo(a) circulate in human plasma and that this fraction of plasma apo(a) is the likely source of the apo(a) fragments in human urine. The largest of the free apo(a) fragments were $\sim 200 \mathrm{kD}$ smaller than the full-length apo(a) isoforms and the sizes of the remaining series of fragments decreased progressively by $25-30 \mathrm{kD}$, which is the estimated size of a K4-type 2 repeat (20). The fragments contained the epitopes for the type 2 but not the type $9 \mathrm{~K} 4$ repeat. These observations are consistent with the apo(a) fragments being derived from the $\mathrm{NH}_{2}$ terminal region of apo(a) and containing variable numbers of the type $2 \mathrm{~K} 4$ repeats. When the free apo(a) fragments were injected into mice, a species that does not synthesize apo(a), the fragments disappeared rapidly from the plasma and were excreted into the urine. The fragments in the urine were of a lower apparent molecular mass and matched the size of the apo(a) fragments in human urine. Taken together, these data strongly suggest that the apo(a) fragments in human urine are derived from fragments that circulate in human plasma.

Apo(a) immunoreactive bands smaller in size than the fulllength apo(a) isoforms are often detected when human plasma is subjected to immunoblotting. In our laboratory, these fragments are most apparent when polyclonal anti-apo(a) antibodies or mAbs directed against epitopes in the apo(a) K4-type 2 repeat region are used for immunoblot analysis of plasma from individuals with low plasma Lp(a) levels. Previously we attributed the presence of these smaller apo(a) immunoreactive bands to artifactual degradation products of apo(a). However, evidence presented here argues that these immunoreactive fragments circulate in normal human plasma and are not an artifact of sample processing. First, the fragments did not change in size or amount in the presence or absence of protease inhibitors or after storage for prolonged time periods. Second, no apo(a) fragments were detected on immunoblot analysis of plasma from transgenic mice expressing Lp(a) that was collected and handled in an identical manner to the human samples. Third, apo(a) fragments were identified in baboon plasma but not in the media from primary cultures of baboon hepatocytes which contain full-length apo(a). Finally, when sera and/or plasma from $\mathrm{Lp}(\mathrm{a})$ transgenic mice and humans were mixed, no increase in the amount of apo(a) fragments was detected (data not shown).

The plasma levels of free apo(a) were related directly to the plasma level of $\mathrm{Lp}(\mathrm{a})$ and to the 24-h urinary excretion of apo(a). There are several possible origins of the free apo(a) fragments found in human plasma. They may be produced by hepatocytes and then secreted into the circulation. The fragments could be differential splice products of the apo(a) gene or could result from incomplete translation of the full-length apo(a) mRNA. Translation of long transcripts, similar in size to that of the apo(a) mRNA, not infrequently terminates prematurely (26). However, the fact that no shorter apo(a) mRNAs have been identified on Northern blot analysis of human, cynomolgus monkey, or baboon liver mRNA $(23,27,28)$ and that the apo(a) fragments vary by the same size interval make these two possibilities unlikely. Finally, no apo(a) fragments were identified in the media of primary cultures of hepatocytes from a baboon who had apo(a) fragments in its plasma. Based on these observations we conclude that the apo(a) fragments are generated either from the full-length free apo(a) or from the apo(a) that is covalently bound to LDL as Lp(a).

White and Lanford (29) have shown that apo(a) and apoB are synthesized independently in primary cultures of baboon hepatocytes and that the disulfide linkage between apo(a) and apo-B100 occurs on the hepatocyte cell surface. The non-lipoprotein-associated apo(a) in plasma may thus represent the subset of apo(a) molecules secreted from the hepatocyte that do not complex properly with apo-B100 to form $\mathrm{Lp}(\mathrm{a})$ and may be the source of the apo(a) fragments. Arguing against this scenario was the finding that individuals with abetalipoproteinemia, who have trace to no apoB in plasma (22), have easily detectable levels of free full-length apo(a) circulating in their plasma and the levels of apo(a) fragments were no higher than the controls (Fig. 8).

It is conceivable that apo(a) fragments are synthesized by extrahepatic tissues, possibly as products of differentially 
spliced forms of apo(a) mRNA. Previously, we have ruled out this possibility for the kidney (13), but not for other tissues. Alternatively, the apo(a) fragments may be generated from circulating apo(a) or Lp(a). Other members of the K-containing family, including macrophage stimulating protein, are secreted as an inactive precursor and then activated in serum or in tissues (30). Apo(a) may also undergo proteolytic cleavage, either in blood or tissues, to produce apo(a) fragments. We have been unable to generate the apo(a) fragments from $\operatorname{Lp}(\mathrm{a})$ using serum or plasma. Nor have we been able to detect the $\mathrm{COOH}$-terminal part of apo(a), which contains the free cysteine residue responsible for the covalent bond to apo-B100 $(31,32)$ and participates in apo(a) binding to lysine $(33,34)$. We have also incubated Lp(a) with human umbilical vein endothelial cells and with HepG2 hepatocarcinoma cells for up to $7 \mathrm{~d}$ and found no fragments in the media or cells (data not shown). Hoff has identified apo(a) immunoreactive fragments in human atherosclerotic plaques (35); it is not known if these fragments are formed locally or produced elsewhere and subsequently adhere to the arterial wall or how they relate to the apo(a) fragments in plasma.

The findings that a significant proportion of the plasma apo(a) is in the form of fragments in individuals with very low plasma levels of $\operatorname{Lp}(\mathrm{a})$ and that the proportion of apo(a) that circulates as fragments falls with increasing levels of Lp(a) suggest that the mechanism responsible for their generation is a high-affinity, low capacity system. This mechanism clearly is not the major pathway by which apo(a) is cleared from plasma, especially in individuals with plasma $\mathrm{Lp}$ (a) levels $>2.0 \mathrm{mg} / \mathrm{dl}$. Nor did we find any evidence that differences in the amount of apo(a) fragments in plasma are responsible for the interindividual and interethnic differences in plasma levels of $\mathrm{Lp}(\mathrm{a})$. For example, African-Americans have two- to threefold higher median plasma levels of $\operatorname{Lp}(\mathrm{a})$ than Caucasians $(19,36,37)$ and yet the amount of free apo(a) relative to the plasma concentration of $\mathrm{Lp}(\mathrm{a})$ and the 24-h urinary excretion of apo(a) is similar in Caucasians and African-Americans (our unpublished observation). Therefore, the higher levels of plasma $\mathrm{Lp}(\mathrm{a})$ in African-Americans cannot be attributed to larger amounts of apo(a) fragments circulating in the plasma or to a decrease in the clearance of these fragments by the kidney.

Apo(a) fragments were detected in the plasma from a cynomolgus monkey and from 9 out of the 10 baboons tested, which are both species that express apo(a). One baboon with a very low plasma $\mathrm{Lp}$ (a) level $(0.1 \mathrm{mg} / \mathrm{dl})$ had no free apo(a) detected in its plasma. This same baboon also had no apo(a) fragments in its urine. This observation reinforces the hypothesis that apo(a) fragments in plasma are the source of urinary apo(a) and also suggests that the limiting step in the generation of apo(a) fragments in urine is the conversion of apo(a)/ $\mathrm{Lp}$ (a) to apo(a) fragments. It is interesting that mice, which do not synthesize apo(a) and cannot process apo(a) or $\mathrm{Lp}(\mathrm{a})$ into fragments, were capable of excreting the apo(a) fragments that circulate in human plasma into the urine. The large size and highly glycosylated nature of these apo(a) fragments argue against the fragments entering the urine via filtration and suggest that the fragments enter the urine by secretion. The mechanisms responsible for the reduction in size of the fragments and the excretion of the fragments into the urine are not known. Apo(a) may resemble another mouse protein and may use its transport system to enter mouse urine. Identification of such a murine protein homologue may provide insights into the physiological role of apo(a), which remains a central mystery in the study of this enigmatic apolipoprotein.

In this regard, the physiological and pathophysiological consequences of having apo(a) fragments in the circulation remain to be established. The data presented here do not provide any functional role for these fragments. However, these studies reveal a new pathway by which $\mathrm{Lp}(\mathrm{a}) / \mathrm{apo}(\mathrm{a})$ may be biologically active and may promote the development of atherosclerosis. $\mathrm{Lp}$ (a) may have been designed as a reservoir for the delivery of apo(a) fragments to tissues where they may act as agonist or antagonists for receptors of other K-containing peptides. However, at this time we cannot rule out that these fragments are simply a by-product of apo(a) degradation.

In summary, we provide evidence that a portion of apo(a)/ $\mathrm{Lp}(\mathrm{a})$ that circulates in plasma undergoes proteolytic cleavage by a high-affinity/low-capacity mechanism that is present in both humans and monkeys, but not in mice. Some, if not all, of the apo(a) fragments produced by this mechanism are taken up by the kidney, processed to generate smaller fragments, and then the smaller fragments are excreted into the urine by a yet-to-be-identified mechanism that is operative not only in humans and monkeys, but also in mice. The presence of this clearance mechanism in mice, a species that does not produce apo(a), suggests that there may be a conserved transport mechanism that may excrete another murine protein that shares structural similarity to apo(a).

Finally, if the apo(a) fragments in plasma are the source of the apo(a) fragments in urine, it would be expected that individuals with chronic renal failure (CRF) would have higher levels of plasma apo(a) fragments. Individuals on hemodialysis have between 1.5- and 2-fold higher plasma levels of $L p(a)$ (38-41). Are the higher plasma levels of free apo(a) in the CRF subjects responsible for the increase in plasma Lp(a) levels seen in these subjects? Studies are in progress to examine this possibility and the preliminary results suggest that the plasma levels of apo(a) fragments are significantly elevated in humans with CRF but that this elevation accounts for only a modest portion of the observed increase in plasma apo(a) levels in subjects with CRF.

\section{Acknowledgments}

We thank David Russell, Jonathan Cohen, Miguel Seabra, and Stephen Young for helpful discussions. Also, we wish to thank Robert Hammer for assistance with the mouse studies and Laura Fuller for preparation of the manuscript.

This work was supported by grants from the National Institutes of Health (HL-47619 to H.H. Hobbs and HL-30086 to S.M. Marcovina), the Perot Family Fund, and the Keck Foundation. V. Mooser is a recipient of a scholarship from the Swiss Academy for Medical Sciences and the SICPA Foundation, Lausanne, Switzerland.

\section{References}

1. Utermann, G. 1995. Lipoprotein(a). In The Metabolic Basis of Inherited Disease. C.R. Scriver, A.L. Beaudet, W.S. Sly, and D. Valle, editors. McGraw Hill Inc., New York. 1887-1912.

2. Scanu, A.M. 1991. Lipoprotein(a) and atherosclerosis. Ann. Intern. Med. 115:209-218.

3. Liu, A.C., and R.M. Lawn. 1994. Vascular interactions of lipoprotein(a). Curr. Opin. Lipidol. 5:269-273.

4. Ikeo, K., K. Takahashi, and T. Gojobori. 1995. Different evolutionary histories of kringle and protease domains in serine proteases: a typical example of domain evolution. J. Mol. Evol. 40:331-336.

5. Yoshimura, T., N. Yuhki, M. Wang, A. Skee, and E.J. Leonard. 1993. 
Cloning, sequencing, and expression of human macrophage stimulating protein (MSP, MST1) confirms MSP as a member of the family of kringle proteins and locates the MSP gene on chromosome 3. J. Biol. Chem. 268:15461-15468.

6. Morrisett, J., J. Gaubatz, R. Knapp, and J.G. Guevara. 1990. Structural properties of apo(a): a major apoprotein of human lipoprotein(a). In Lipoprotein(a). A. Scanu, editor. Academic Press, Inc., San Diego, CA. 53-74.

7. Lackner, C., J.C. Cohen, and H.H. Hobbs. 1993. Molecular definition of the extreme size polymorphism in apolipoprotein(a). Hum. Mol. Genet. 2:933940 .

8. McLean, J.W., J.E. Tomlinson, W.J. Kuang, D.L. Eaton, E.Y. Chen, G.M. Fless, A.M. Scanu, and R.M. Lawn. 1987. cDNA sequence of human apolipoprotein(a) is homologous to plasminogen. Nature (Lond.). 330:132-137.

9. Van der Hoek, Y., W. Sangrar, G.P. Côté, J.J.P. Kastelein, and M.L. Koschinsky. 1994. Binding of recombinant apolipoprotein(a) to extracellular matrix proteins. Arterioscler. Thromb. 14:1792-1798.

10. Mizuno, K., H. Inoue, M. Hagiya, S. Shimizu, T. Nose, Y. Shimohigashi, and T. Nakamura. 1994. Hairpin loop and second kringle domain are essential sites for heparin binding and biological activity of hepatocyte growth factor. $J$. Biol. Chem. 269:1131-1136.

11. O'Reilly, M.S., L. Holmgren, Y. Shing, C. Chen, A. Rosenthal, M. Moses, W.S. Lane, Y. Cao, E.H. Sage, and J. Folkman. 1994. Angiostatin: a novel angiogenesis inhibitor that mediates the suppression of metastases by a Lewis lung carcinoma. Cell. 79:315-328.

12. Oida, K., H. Takai, H. Maeda, S. Takahashi, A. Shimada, J. Suzuki, T. Tamai, T. Nakai, and S. Miyabo. 1992. Apolipoprotein(a) is present in urine and its excretion is decreased in patients with renal failure. Clin. Chem. 38: 2244-2248.

13. Mooser, V., M.C. Seabra, M. Abedin, K.T. Landschulz, S. Marcovina, and H.H. Hobbs. 1996. Apo(a) kringle 4-containing fragments in human urine. Relationship to plasma levels of lipoprotein(a). J. Clin. Invest. 97:858-864.

14. Marcovina, S.M., J.J. Albers, B. Gabel, M.L. Koschinsky, and V.P. Gaur. 1995. Effect of the number of apolipoprotein(a) kringle 4 domains on immunochemical measurements of lipoprotein(a). Clin. Chem. 41:246-255.

15. Chiesa, G., H.H. Hobbs, M.L. Koschinsky, R.M. Lawn, S.D. Maika, and R.E. Hammer. 1992. Reconstitution of lipoprotein(a) by infusion of human low density lipoprotein into transgenic mice expressing human apolipoprotein(a).J. Biol. Chem. 267:24369-24374.

16. Linton, M.F., R.V. Farese, G. Chiesa, D.S. Grass, P. Chin, R.E. Hammer, H.H. Hobbs, and S.G. Young. 1993. Transgenic mice expressing high plasma concentrations of human apolipoprotein B100 and lipoprotein(a). $J$. Clin. Invest. 93:3029-3037.

17. Rainwater, D.L., G.S. Manis, and J.L. VandeBerg. 1989. Hereditary and dietary effects on apolipoprotein(a) isoforms and $\mathrm{Lp}$ (a) in baboons. J. Lipid Res. 30:549-558.

18. Lanford, R.E., K.D. Carey, L.E. Estlack, G.C. Smith, and R.V. Hay. 1989. Analysis of plasma protein and lipoprotein synthesis in long-term primary cultures of baboon hepatocytes maintained in serum-free medium. In Vitro Cell. Dev. Biol. 25:174-182.

19. Gaw, A., E. Boerwinkle, J.C. Cohen, and H.H. Hobbs. 1994. Comparative analysis of the apo(a) gene, apo(a) glycoprotein and plasma concentrations of $\mathrm{Lp}(\mathrm{a})$ in three ethnic groups. Evidence for no common "null" allele at the apo(a) locus. J. Clin. Invest. 93:2526-2534.

20. Koschinsky, M.L., J.E. Tomlinson, T.F. Zioncheck, K. Schwartz, D.L. Eaton, and R.M. Lawn. 1991. Apolipoprotein(a): expression and characterization of a recombinant form of the protein in mammalian cells. Biochemistry. 30: 5044-5051.

21. Young, S.G., S.J. Bertics, L.K. Curtiss, and J.L. Witztum. 1987. Characterization of an abnormal species of apolipoprotein B, apolipoprotein B-37, associated with familial hypobetalipoproteinemia. J. Clin. Invest. 79:1831-1841

22. Menzel, H.J., H. Dieplinger, C. Lackner, F. Hoppichler, J.K. Lloyd, D.R. Muller, C. Labeur, P.J. Talmud, and G. Utermann. 1990. Abetalipoproteinemia with an apoB-100-lipoprotein(a) glycoprotein complex in plasma. Indication for an assembly defect. J. Biol. Chem. 265:981-986.
23. Azrolan, N., D. Gavish, and J.L. Breslow. 1991. Plasma lipoprotein(a) concentration is controlled by apolipoprotein(a) (Apo(a)) protein size and the abundance of hepatic apo(a) mRNA in a cynomolgus monkey model. J. Biol. Chem. 266:13866-13872.

24. Kraft, H.G., H.J. Menzel, F. Hoppichler, W. Vogel, and G. Utermann. 1989. Changes in genetic apolipoprotein phenotypes caused by liver transplantation. Implications for apolipoprotein synthesis. J. Clin. Invest. 83:137-142.

25. Callow, M.J., J. Verstuyft, R. Tangirala, W. Palinski, and E.M. Rubin. 1995. Atherogenesis in transgenic mice with human apolipoprotein B and lipoprotein(a). J. Clin. Invest. 96:1639-1646.

26. Farabaugh, P.J. 1993. Alternative readings of the genetic code. Cell. 74: 591-596.

27. Koschinsky, M.L., U. Beisiegel, D. Henne-Bruns, D.L. Eaton, and R.M. Lawn. 1990. Apolipoprotein(a) size heterogeneity is related to variable number of repeat sequences in its mRNA. Biochemistry. 29:640-644.

28. Hixon, J.E., M.L. Britten, G.S. Manis, and D.L. Rainwater. 1989. Apolipoprotein(a) (apo(a)) glycoprotein isoforms result from size differences in apo(a) mRNA in baboons. J. Clin. Invest. 264:6013-6016.

29. White, A.L., D.L. Rainwater, and R.E. Lanford. 1993. Intracellular maturation of apolipoprotein(a) and assembly of lipoprotein(a) in primary baboon hepatocytes. J. Lipid Res. 34:509-517.

30. Wang, M., A. Skeel, and E.J. Leonard. 1996. Proteolytic cleavage and activation of pro-macrophage-stimulating protein by resident peritoneal macrophage membrane proteases. J. Clin. Invest. 97:720-727.

31. Koschinsky, M.L., G.P. Côté, B. Gabel, and Y.Y. Van der Hoek. 1993. Identification of the cysteine residue in apolipoprotein(a) that mediates extracellular coupling with apolipoprotein B-100. J. Biol. Chem. 268:19819-19825.

32. Brunner, C., H.G. Kraft, G. Utermann, and H.J. Muller. 1993. Cys4057 of apolipoprotein(a) is essential for lipoprotein(a) assembly. Proc. Natl. Acad. Sci. USA. 90:11643-11647.

33. Ernst, A., M. Helmhold, C. Brunner, A. Pethö-Schramm, V.W. Armstrong, and H. Müller. 1995. Identification of two functionally distinct lysinebinding sites in kringle 37 and in kringle 32-36 of human apolipoprotein(a). $J$. Biol. Chem. 270:6227-6234.

34. Scanu, A.M., L.A. Miles, G.M. Fless, D. Pfaffinger, J. Eisenbart, E. Jackson, J.L. Hoover-Plow, T. Brunck, and E.F. Plow. 1993. Rhesus monkey lipoprotein(a) binds to lysine Sepharose and U937 monocytoid cells less efficiently than human lipoprotein(a). J. Clin. Invest. 91:283-291.

35. Hoff, H.F., J. O'Neil, and A. Yashiro. 1993. Partial characterization of lipoproteins containing apo(a) in human atherosclerotic lesions. J. Lipid Res. 34:789-798.

36. Guyton, J.R., G.H. Dahlen, W. Patsch, J.A. Kautz, and A. Gotto, Jr. 1985. Relationship of plasma lipoprotein $\mathrm{Lp}$ (a) levels to race and to apolipoprotein B. J. Clin. Invest. 5:265-272.

37. Sandholzer, C., E. Boerwinkle, N. Saha, M.C. Tong, and G. Utermann. 1992. Apolipoprotein(a) phenotypes, Lp(a) concentration and plasma lipid levels in relation to coronary heart disease in a Chinese population. Evidence for the role of the apo(a) gene in coronary heart disease. J. Clin. Invest. 89:10401046.

38. Parra, H.J., H. Mezdour, C. Cachera, M. Dracon, A. Tacquet, and J.C. Fruchart. 1987. Lp(a) lipoprotein in patients with chronic renal failure treated by hemodialysis. Clin. Chem. 33:721.

39. Haffner, S.M., K.K. Gruber, G. Aldrete, Jr., P.A. Morales, M.P. Stern, and K.R. Tuttle. 1992. Increased lipoprotein(a) concentrations in chronic renal failure. J. Am. Soc. Nephrol. 3:1156-1162.

40. Dieplinger, H., C. Lackner, F. Kronenberg, C. Sandholzer, K. Lhotta, F. Hoppichler, H. Graf, and P. Konig. 1993. Elevated plasma concentrations of lipoprotein(a) in patients with end-stage renal disease are not related to the size polymorphism of apolipoprotein(a). J. Clin. Invest. 91:397-401.

41. Hirata, K., S. Kikuchi, K. Saku, S. Jimi, B. Zhang, S. Naito, H. Hamaguchi, and K. Arakawa. 1993. Apolipoprotein(a) phenotypes and serum lipoprotein(a) levels in maintenance hemodialysis patients with/without diabetes mellitus. Kidney Int. 44: 1062-1070. 